Abstracta Iranica Abstracta Iranica

Revue bibliographique pour le domaine irano-aryen

Volume 34-35-36 | 2017

Comptes rendus des publications de 2011-2013

\title{
Shahrokh Razmjou. Left Unfinished: The 'Unfinished Gate' of Persepolis as Key Evidence for Architectural and Construction Procedure at Persepolis
}

\section{Astrid Nunn}

\section{(2) OpenEdition \\ Journals}

Édition électronique

URL : http://journals.openedition.org/abstractairanica/41675

DOI : 10.4000/abstractairanica.41675

ISSN : 1961-960X

Éditeur :

CNRS (UMR 7528 Mondes iraniens et indiens), Éditions de l'IFRI

Référence électronique

Astrid Nunn, «Shahrokh Razmjou. Left Unfinished: The 'Unfinished Gate' of Persepolis as Key Evidence for Architectural and Construction Procedure at Persepolis », Abstracta Iranica [En ligne], Volume 34-35-36 |

2017, document 78, mis en ligne le 15 juillet 2016, consulté le 29 septembre 2020. URL : http:// journals.openedition.org/abstractairanica/41675; DOI : https://doi.org/10.4000/abstractairanica. 41675

Ce document a été généré automatiquement le 29 septembre 2020

Tous droits réservés 


\title{
Shahrokh Razmjou. Left Unfinished: The 'Unfinished Gate' of Persepolis as Key Evidence for Architectural and Construction Procedure at Persepolis
}

\author{
Astrid Nunn
}

\section{RÉFÉRENCE}

Shahrokh Razmjou. « Left Unfinished: The 'Unfinished Gate' of Persepolis as Key Evidence for Architectural and Construction Procedure at Persepolis ", in : H. D. Baker, K. Kaniuth, A. Otto, eds., Stories of Long Ago, Festschrift für Michael D. Roaf. Münster, Ugarit-Verlag, 2012, p. 481-495. (AOAT 397)

Un des bâtiments non terminé du " méga chantier » de Persépolis est la " Porte inachevée » située à $120 \mathrm{~m}$ à l'est de la «Porte de toutes les nations» et à environ $60 \mathrm{~m}$ au nord du portique d'entrée du Palais des 100 colonnes. Son état provisoire la rend intéressante pour l'analyse des techniques de construction. Les blocs dégrossis étaient sculptés sur place, puis en partie assemblés et polis du haut vers le bas. Les éléments de colonnes étaient pourvus de marques, qui souvent étaient effacées peu avant le montage. L'emplacement exigu ne permet pas d'y monter une rampe. Des traces de cordages sur certains tambours poussent l'A. à penser que les colonnes étaient montées à l'aide d'un échafaudage. La construction de cette porte, sans doute interrompue par la conquête d'Alexandre le Grand, ne pourrait avoir été commanditée qu'au IV ${ }^{\text {e }}$ s. Sa raison d'être reste obscure. 


\section{AUTEURS}

\section{ASTRID NUNN}

Université de Munich 